\title{
Insertion of intrauterine devices after cesarean section: a systematic review update
}

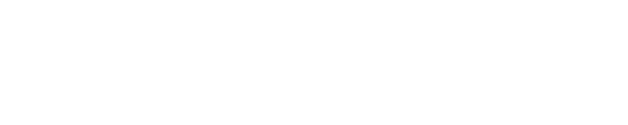

\author{
Norman D Goldstuck' \\ Petrus S Steyn ${ }^{2}$ \\ 'Department of Obstetrics and \\ Gynaecology, Faculty of Medicine \\ and Health Sciences, Stellenbosch \\ University, Tygerberg Hospital, \\ Western Cape, ${ }^{2}$ Department of \\ Obstetrics and Gynaecology, \\ University of Cape Town, \\ Cape Town, South Africa
}

Correspondence: Norman D Goldstuck Department of Obstetrics and Gynaecology, Faculty of Medicine and Health Sciences, Stellenbosch University, 100 Francie van Zyl Street, Cape Town, South Africa

Email nahumzh@gmail.com
Background: Women who undergo a cesarean section (CS) are in a unique position to receive the intrauterine contraceptive device (IUD). They may also want to use the IUD as a longacting reversible contraceptive method provided the IUD is safe and effective in the presence of a CS scar.

Search strategy: We researched and reviewed the MEDLINE, POPLINE, Google Scholar, and ClinicalTrials.gov databases from January 1968 to June 2015.

Selection criteria: Eligible studies reported event rates or practical problems relating to IUD usage in post-placental or interval insertion ( $>90$ days) after CS. Studies with $\geq 20$ subjects were included.

Data collection and analysis: Analysis of eligible data collected from the search followed the PRISMA guidelines.

Main results: Twelve eligible studies of post-placental IUD insertion after CS included four randomized controlled trials of post-placental versus delayed insertion. Women randomized to delayed insertion were less likely to receive a device. Six studies examined the problem of missing IUD threads at follow-up with only 30\%-60\% presence of strings observed.

Conclusion: The IUD is a long-acting reversible contraceptive method that is suitable for use in all women undergoing CS. The problems of device expulsion, missing threads at follow-up, and the tendency of increased puerperal bleeding need to be solved. Solutions are proposed.

Keywords: post-placental IUD, cesarean section, missing IUD threads, IUD expulsion, longacting reversible contraception

\section{Introduction}

LARC is the most clinically and economically effective type of contraception. ${ }^{1,2}$ Implants and IUDs have a rapid action of onset after administration with a rapid return to fertility after discontinuation. ${ }^{3,4}$ LARC methods are therefore ideally suited to play a major role in fertility regulation worldwide as well as in Global South (GS) or impoverished countries.

CS rates are rising in all countries, including those of the GS. ${ }^{5}$ IUD insertion at the time of CS creates an opportunity to increase access to LARC methods. Conversely, a previous CS scar may deter access to interval insertion of an IUD if a previous CS may result in difficulty with insertion and/or future IUD problems. We updated a previous systematic review ${ }^{6}$ to see if post-placental and interval IUD insertion could be made more accessible for women wanting to use this method.

Even though it has only been a few years since our initial review, there have been a number of new detailed studies in this area. ${ }^{7-21}$ The later, newer studies are constructed and some are controlled so that we are able to get a better understanding of how best to utilize the post-placental CS opportunity, and how to deal with the CS scar in those 
women who want an IUD after having previously had a CS. This review updates our previous analysis of insertion of IUDs in women who have had a CS and where IUD insertion has been post-placental or interval.

\section{Methods}

This study is a systematic review to evaluate complications and performance after an IUD is inserted into women who have had a CS. There are two main categories: 1) insertion at the time of CS, ie, PPIUDCS and 2) interval inser$\operatorname{tion}^{6}$ (42 days or more after CS [IIUDCS]).

In more recent studies this distinction may have become slightly blurred since the newer studies have subjects in both groups ie, post-partum and very early interval, as they are controlled and compare post-placental insertion with 6- to 8 -week post-partum insertion as a control group. ${ }^{12,13}$ The control group thus "straddles" the boundary of post-partum and interval ${ }^{6}$ insertion. We will consider these as interval insertions (IIUDCS) as opposed to post-placental insertions, since post-placental insertions are defined by being able to place the device in the uterine cavity under direct vision, the only time it is possible to do this. The straddled insertions at 6-12 weeks post-partum have been added to the to the IIUDCS group.

The methods used for data collection have been described in the previous study ${ }^{6}$ and included both controlled and uncontrolled studies, but were modified as described in the following section. The reference list for this study was generated from searching for references from the following databases: MEDLINE: "Intrauterine device (IUD, IUCD)"/“Intrauterine system (IUS) [MeSH]" AND "Cesarean section, caesarean section $\mathrm{CS}, \mathrm{C} / \mathrm{S}$ [MeSH]". "Intrauterine device (IUD, IUCD)"/“"Intrauterine system (IUS)". POPLINE: "IUD” AND "cesarean section". PubMed: "IUD” AND “cesarean section". Google Scholar: "IUD”, "IUS” AND “post-placental cesarean section", AND "IUD” AND "interval cesarean section", the terms were filtered so as not to overlap in the advanced search. ClinicalTrials.gov: "intrauterine device" AND "cesarean section". We did not search Wangfang Data and Weipu Data. Significant Chinese articles are beginning to appear in English language databases. Our study updates peer-reviewed papers from January 1968 to December 2012, which formed the basis of the previous report. In that study we searched for references from January 1968 to December 2012. The current search was divided into two parts: 1) to see if new references (especially foreign language) were added to the databases during that period (January 1968 to December 2012); and 2) to do an updated search from December 2012 to June 2015. This latter search is the main focus of this report.
The inclusion criteria for selection of studies were broadened. Previously, we only included studies that contained principal event rates (pregnancy, expulsion, medical removal, and continuation rate) in at least 20 subjects. In this study we have included clinical complications such as pain, bleeding, discomfort, missing strings, and any other adverse reports in studies of $\geq 20$ subjects. The systematic review section was conducted following the PRISMA guidelines, ${ }^{22}$ a flow chart of selection of articles from January 2013 to June 2015 is given in Figure 1. We did not search the Chinese databases, but we actively searched for non-English articles that are increasingly being added to current databases, especially POPLINE. Higher weighting was given to RCTs and those with higher degrees of evidence, as indicated in the PRISMA guidelines. ${ }^{22}$ These types of studies are now more common, as interest is growing in this area. We found two Chinese ${ }^{23,24}$ and one Malaysian study $^{25}$ in the PPIUDCS group prior to December 2012, and one Chinese study in the IIUDCS group. The January 2013 to June 2015 search produced 12 papers in the PPIUDCS group, and two in the IIUDCS group. The selection process is given in Figure 1.

The previously missing references were found by repeating the POPLINE search, which found the new references that had been added by POPLINE to their database in the interim. These references have been added to our earlier database, and the table of post-partum CS insertion from our earlier paper has been updated (Table 1). Summary odds ratios were not computed because of the highly nonhomogeneous data reporting methods.

\section{Results}

The search of the older references added a Lippes loop (Ortho, Raritan, NJ, USA) study in Malaysia, ${ }^{25}$ a Chinese study of the GyneFix PP (Contrel Europe NV, Ghent, Belgium), ${ }^{23}$ and an RCT of the Fix-T-Cu 220C-M and the Delta T-Cu220C to the PPIUDCS group. These have been added to the old database of experience (January 1968 to December 2012) and are presented in Table 1. ${ }^{26-39}$ There was one IIUDCS study of the VCu200 IUD, which was a comparative study of subjects who had a CS versus those who had not had a CS at 42-90 days post-partum. This study has been added to the previous studies of mostly older IUDs. ${ }^{6}$ In the $\mathrm{VCu} 200$ study, there was one ectopic pregnancy $(0.32 \%)$ and at 2-year follow-up the expulsion rate was 2.68 per 100 woman years of use for the CS group, and 2.65 for the non-CS group. The pregnancy rate for the CS group was 4.49, and 5.88 for the non-CS group per 100 woman years of use, as determined by life table analysis. The tendency, 
Selection of relevant articles for intrauterine device insertion after cesarean section

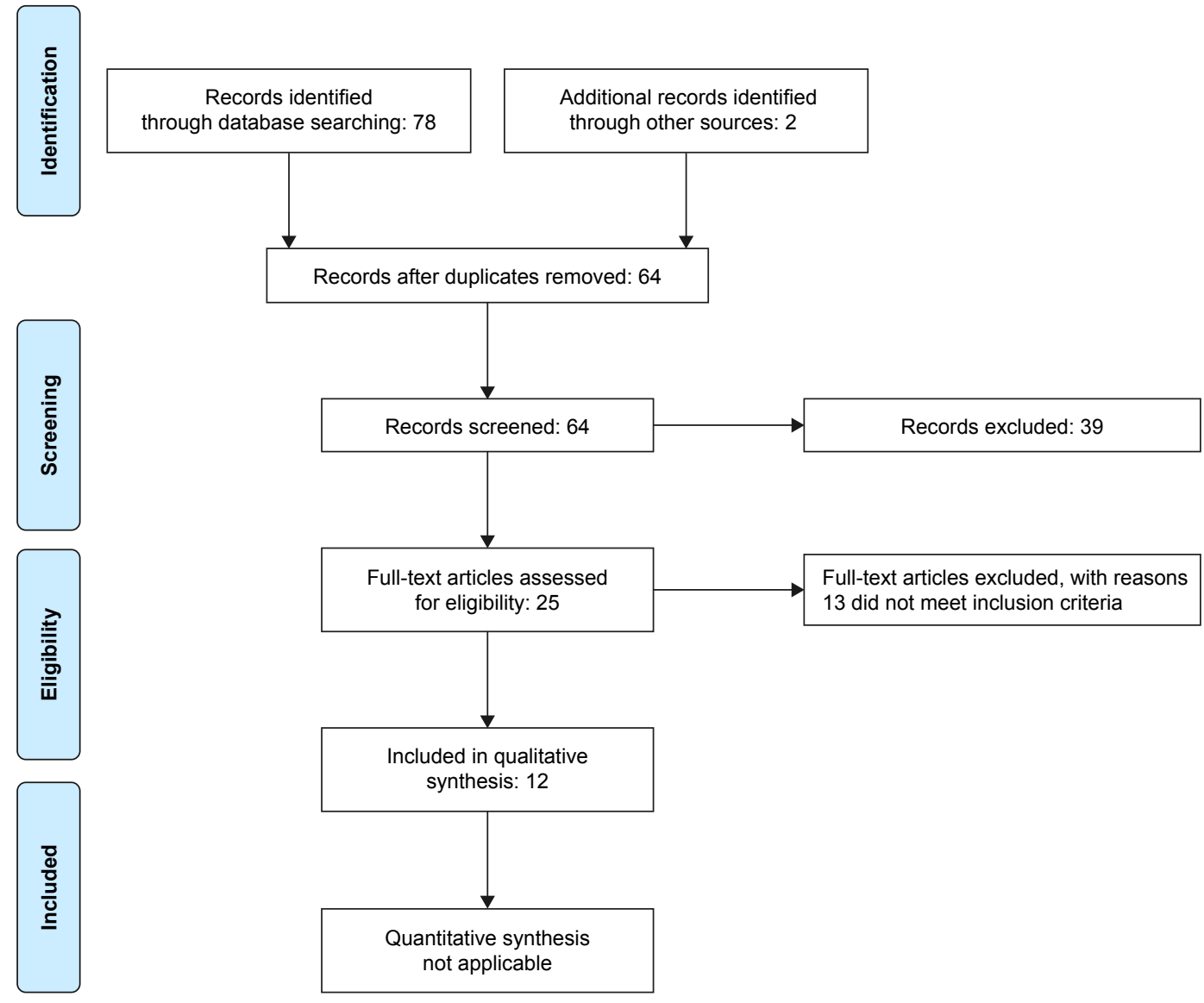

Figure I Flow chart of selection of articles from December 2012 to June 2015 (PRISMA).

Abbreviation: PRISMA, Preferred Reporting Items for Systematic Reviews and Meta-Analyses.

since the end period of the last review (from 2013 onwards), has been a move to controlled studies of different IUDs with different time periods in the PPIUDCS groups. It is this information which can provide the "which" and the "when" for PPIUDCS and IIUDCS insertion, and can help improve clinical practice.

Ten studies from the January 2013 to June 2015 search met the criteria for inclusion in the PPIUDCS group, the

Table I Updated PPIUDCS studies published before December 2012

\begin{tabular}{|c|c|c|c|c|c|c|}
\hline \multicolumn{7}{|c|}{ Event rate per I 00 woman years (range) } \\
\hline Type of IUD & Studies & $\begin{array}{l}\text { Subjects } \\
\text { followed }\end{array}$ & Expulsion & $\begin{array}{l}\text { Medical } \\
\text { removal }\end{array}$ & Pregnancy & Comments and references \\
\hline Mirena & I & 33 & 0 & 0 & 0 & I2-month follow-up ${ }^{27}$ \\
\hline MLCu 250 & I & 154 & $2.6 \%$ & $7.8 \%$ & 0 & I2-month percentage rate ${ }^{28}$ \\
\hline TCu220 & 3 & 714 & $(1.78-10.9)$ & Not stated & $0-1.1$ & I2-month cumulative rate ${ }^{29-31}$ \\
\hline TCu380A & 5 & 314 & $(0-17.6)$ & $(0-10.6)$ & 0 & One study had 6-month follow-up ${ }^{32-36}$ \\
\hline Delta $\mathrm{T}$ & 2 & 135 & $(4.1-9.6)$ & 7.2 & 2.4 & One reported 6-month cumulative, the \\
\hline Delta loop & & & & & & other 24-month percentage rates ${ }^{37,38}$ \\
\hline \multicolumn{7}{|l|}{ Delta Beijing } \\
\hline GyneFix PP IUDa & I & 200 & $4 \%$ & Not stated & 0 & 3-month percentage rates $^{23}$ \\
\hline Fix-T-Cu 220C-Ma & I & 200 & $2.2 \%$ & $2.5 \%$ & $0.5 \%$ & $\mathrm{RCT}$ at 30 months. 30 -month \\
\hline Delta-TCu 220C & & 200 & $10.5 \%$ & $2.6 \%$ & $0.5 \%$ & cumulative life table rates ${ }^{24}$ \\
\hline Metal ring-catgut knots & 7 & 3,131 & $(1.2-9.6)$ & $(0.8-7.2)$ & $(0-7.5)$ & Cumulative rate from 6-24 months ${ }^{38,39}$ \\
\hline Lippes loopa & I & 204 & $12.2 \%$ & $3.9 \%$ & $0.49 \%$ & I2-month percentage rates ${ }^{25}$ \\
\hline
\end{tabular}

Notes: a Newly added studies. Chi et a ${ }^{38}$ reported nine Chinese studies that were also reported in Chi et a ${ }^{37}$ and Liu et al. ${ }^{39}$ The data were only used once. Mirena (Bayer AG, Levekusen, Germany); MLCU 250 (Multilan SA, Fribourg, Switzerland); TCu220 (Population Council, New York, NY, USA); TCu380A (Teva Pharmaceuticals, Petach Tikva, Israel); (Delta T, Delta loop, Delta Beijing, [Chinese government, Beijing, People's Republic of China]); Lippes loop (Ortho, Raritan, NJ, USA); GyneFix PP (Contrel Europe NV, Ghent, Belgium); (Fix-T-Cu 220C-M, Delta-TCu 220C, [Chinese Government, Beijing, People's Republic of China]).

Abbreviations: PPIUDCS, post-placental IUD at CS; CS, cesarean section; IUD, intrauterine contraceptive device; RCT, randomized controlled trial. 
selection process is shown in Figure 1. Two studies met the inclusion criteria in the IIUDCS group. ${ }^{8,16}$ These two studies, which examined the use of interval IUD insertion in women who had had a previous CS, were designed to examine insertion problems rather than event rates. The first study ${ }^{8}$ evaluated pain during insertion of the LNG releasing IUD (LNG IUD) in 28 parous women who had undergone at least one CS compared with 23 nulligravid women and 23 parous women who had not undergone CS. Nulligravid women experienced the most pain, followed by women with previous CS. The second study evaluated the use of misoprostol versus diclofenac before IUD insertion in women who had only given birth by CS. One hundred and thirty women were given misoprostol $400 \mu \mathrm{g}$ sublingually and $100 \mathrm{mg}$ diclofenac orally, while 125 were given diclofenac orally only. ${ }^{16}$ The use of misoprostol in addition to diclofenac did not help with the insertion process. Ease of insertion and pain experienced with the insertion was the same in both groups. Insertion failure rates were similar in both groups. The misoprostol group experienced more abdominal pain and nausea. There were no new studies on expulsion rates in IIUDCS insertions. Our previous data, showing a greater incidence of expulsion with older and much older devices in interval insertion in women with previous $\mathrm{CS},{ }^{6}$ cannot be updated for TCu380A (Teva Pharmaceutical Industries Ltd., Petach Tikva, Israel), LNG IUD, Nova T 380 (Bayer AG, Levekusen, Germany), and GyneFix PP, which are the IUDs in current use.

There were therefore a total of 12 new eligible papers from December 2012 to the present day $\operatorname{search}^{7-17,19-21}$ (10 PPIUDCS and 2 IIUDCS). Our expanded inclusion criteria also allowed us to include two papers from the earlier search that did not meet the previous inclusion criteria. ${ }^{7,10}$ Both were studies that focused on puerperal bleeding, which is of particular relevance in low socioeconomic environments. These two studies have been added to the ten (PPIUDCS) from the later search and are presented in Table 2. There was one RCT of three different devices, Nova T 380, TCu380A, and MLCu 375 (Multiload Copper375; Multilan SA, Fribourg, Switzerland), with significantly lower expulsion rates for the $\mathrm{MLCu}$ 375. ${ }^{14}$ This RCT is the first three-way study that attempts to evaluate which type of IUD is superior, and not assume they behave generically in this situation unless they are tethered to the uterine fundus. ${ }^{20}$ There were four RCTs of PPIUDCS insertion versus interval insertion (at 4-8 weeks). ${ }^{12,13,15,17}$ All had small numbers and limited follow-up. They all showed that those allocated to the delayed insertion group very often failed to present for their later insertion. This was true in both developed countries like Australia, ${ }^{13}$ and GS countries like
Uganda. ${ }^{12}$ One study described a new technique to anchor the IUD to the fundus (hang up) to prevent expulsion, ${ }^{20}$ while one examined elongating threads to help prevent the problem of missing threads. ${ }^{14}$ Expulsion rates were very variable, with no expulsions in studies with very small numbers ${ }^{13,17}$ and where the device was sutured into the uterus, ${ }^{20}$ while in other studies it varied between $10 \%$ and $15 \%$. There were no reports of perforations.

While expulsion and missing strings are important problems everywhere, they are of particular significance for situations in which ultrasound is not available, which is often the case in the GS. Two studies examined the effect of IUD type on puerperal bleeding. ${ }^{7,10}$ LNG IUD was significantly better in reducing puerperal blood loss which is important in helping to prevent anemia, and this is of major importance in areas where undernourishment may be prevalent, as is often the case in the GS.

We have analyzed reports of missing strings from those studies in which it has been detailed. The information that is available is presented in Table 3 and its importance is discussed later. Elongating the threads and guiding them through the cervix results in strings being visible in all cases. ${ }^{14,36}$ For IUDs that have long threads eg, ML Cu375, simply pushing the threads through the cervix at the time of CS produces a $92 \%$ visibility rate at 6 weeks and 6 months. ${ }^{7}$ If the threads of the TCu380A are left at the incision length, then follow-up visibility is around $30 \%-40 \%$. The same is true for the LNG IUD, where string visibility of $30 \%-60 \%$ was reported in two studies. ${ }^{13,15}$ The elongated strings require trimming at follow-up. Missing strings require that the presence and position of the IUD be verified by ultrasound, which as previously stated, is a big problem for clinics in GS countries. There were 70 LNG IUDs placed at 6 weeks post-partum after CS in three studies ${ }^{13,15,17}$ and 22 TCu380A IUDs. ${ }^{12,15}$ At 6-month follow-up there were seven LNG IUD expulsions and one expulsion in the TCu380A group. Losses to follow-up of around 14\% were analyzed using the "intention to treat" method.

\section{Discussion}

The first study on the use of PPIUDCS was by Zerzavy in 1967. ${ }^{40}$ He inserted a Birnberg Bow size 5 or 7 and sutured it in place at CS. After that there were relatively few studies over many years. The main reason for this is that IUDs were firmly in the shadow of the infection scare. The risks of the procedure appeared to override the potential benefits. Sporadic attempts to revive the procedure were made in the 1970s and 1980s. This anxiety regarding PPIUDCS began 


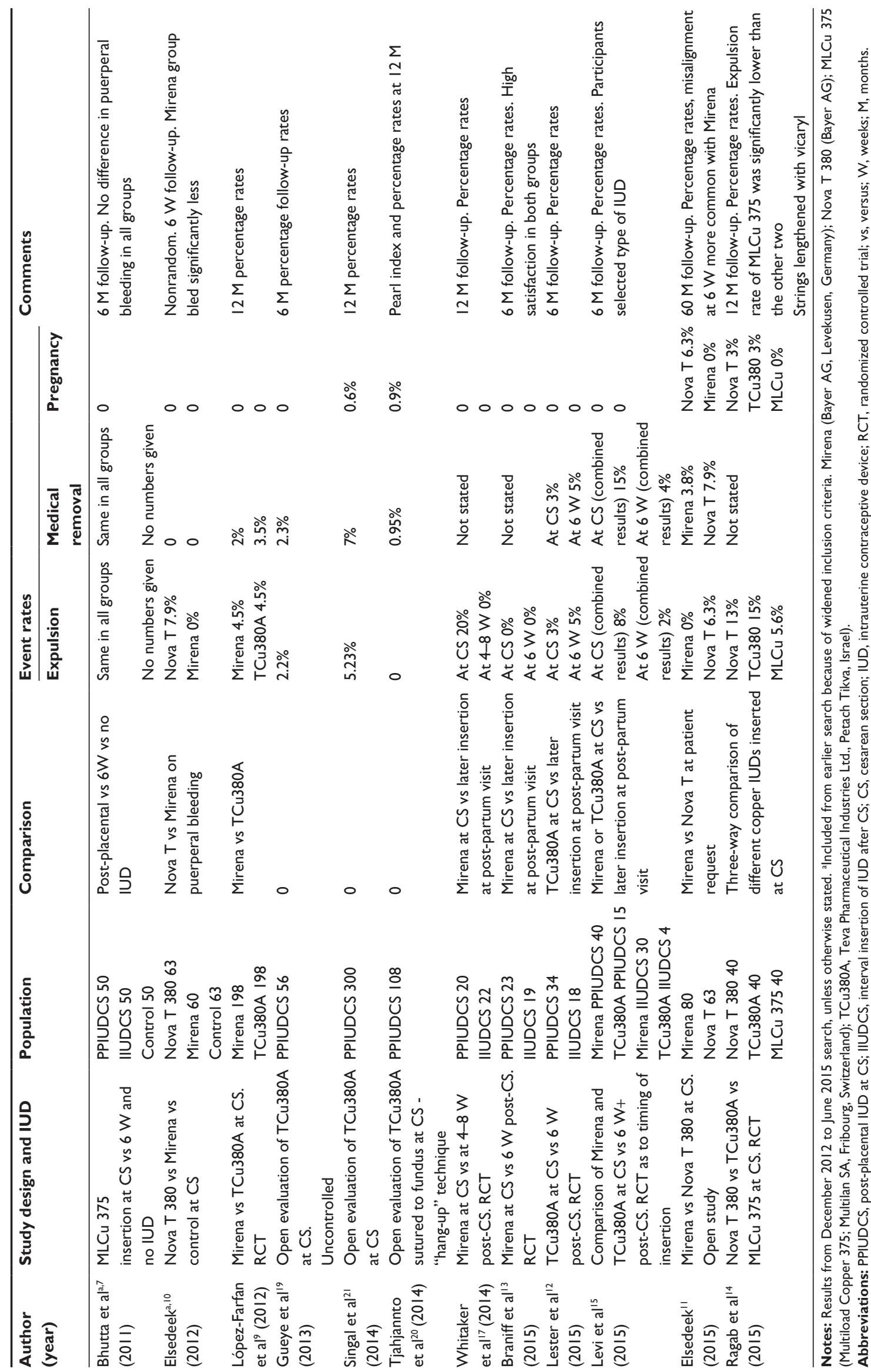


Table 3 Missing strings after PPIUDCS

\begin{tabular}{|c|c|c|c|c|c|}
\hline Study & IUD & Number & $\begin{array}{l}\text { Strings } \\
\text { observed (\%) }\end{array}$ & $\begin{array}{l}\text { Interval after } \\
\text { insertion }\end{array}$ & Comments \\
\hline Zhang $\mathrm{H}$ et $\mathrm{a}^{23}$ & GyneFix PP & 200 & 86 & $6 \mathrm{~W}$ & The device is attached to the fundus under direct vision \\
\hline Nelson et $\mathrm{al}^{36}$ & TCu380A & 7 & 100 & $6 \mathrm{~W}$ & Modified extended strings guided through cervix into vagina \\
\hline Levi et $\mathrm{al}^{34}$ & TCu380A & 32 & 28 & $6 \mathrm{~W}$ & Normal strings placed in the cervix \\
\hline Lester et al ${ }^{12}$ & TCu380A & 27 & 44 & $6 \mathrm{~W}$ & \\
\hline Bhutta et $\mathrm{al}^{7}$ & MLCu 375 & 50 & 92 and 92 & $6 \mathrm{~W}$ and $6 \mathrm{M}$ & Long thread of MLCu 375 pushed through the cervix \\
\hline Singal et $\mathrm{al}^{21}$ & TCu380A & 300 & 61 and 84 & $6 \mathrm{~W}$ and $12 \mathrm{M}$ & More strings seen at $12 \mathrm{M}$ follow-up \\
\hline Braniff et $\mathrm{al}^{13}$ & Mirena & 23 & 31.6 & $6 \mathrm{~W}$ & Strings not directed through the cervix \\
\hline \multirow[t]{2}{*}{ Levi et al ${ }^{15}$} & Mirena & 21 & 67 & $6 M$ & \\
\hline & TCu380A & 10 & 40 & $6 M$ & \\
\hline \multirow[t]{3}{*}{ Ragab et $\mathrm{al}^{1 / 4}$} & Nova T 380 & 40 & 100 & $6 \mathrm{~W}$ and $60 \mathrm{~W}$ & Strings lengthened with vicryl and placed through cervix \\
\hline & MLCu 375 & 40 & 100 & & into the vagina \\
\hline & TCu380A & 40 & 100 & & \\
\hline
\end{tabular}

Notes: Mirena (Bayer AG, Levekusen, Germany); Nova T 380 (Bayer AG); MLCu 375 (Multiload Copper375; Multilan SA, Fribourg, Switzerland); GyneFix PP (Contrel Europe NV, Ghent, Belgium).

Abbreviations: PPIUDCS, post-placental IUD at CS; IIUDCS, interval insertion of IUD after CS; CS, cesarean section; IUD, intrauterine contraceptive device; W, weeks; M, months.

to dissipate in the 1990s due to the realization that the IUD is not primarily responsible for causing infection ${ }^{41}$ and the introduction of the LNG IUD/IUS (Mirena). More recently there has been renewed interest in LARC, because of its well described role in limiting unintended pregnancies. ${ }^{1}$ Inserting an IUD at the time of CS is a very attractive option. It adds very little time and cost to the procedure. The patient does not have to come back especially for follow-up, and there is no risk of primary perforation (secondary perforation is possible) as it is performed under direct vision. Should it remain in place a 5-year follow-up seems to indicate that it will behave similarly to interval insertion in woman with and without $\mathrm{CS} .{ }^{14}$

There appears to be two early problems with PPIUDCS. Initial expulsion rates, although not as high as those after vaginal birth post-partum insertion, are still unacceptably high $(5 \%-10 \%)$. This is the only time an IUD is inserted into the uterine cavity under direct vision, and the use of the correct anchor has the ability to make the expulsion rate close to zero. ${ }^{20,42,43}$ If a method to hold the IUD in the uterus is used, eg, with suturing into the uterine muscle techniques, ${ }^{20}$ expulsion can be reduced to below $1 \%$. This adds to the complexity of the procedure, and in most cases requires additional training for those inserting the devices. The second problem of importance is missing threads. In many GS situations ultrasound is often not available, making this a time-consuming problem which often mandates referral to a tertiary center. Techniques for lengthening threads to ensure their presence in the vagina exist, but often necessitate trimming and so may require an extra post-partum follow-up. However, this is easier to undertake than referral for ultrasound, and post-partum evaluation should be conducted anyway, but even this can create difficulties in the GS. ${ }^{14,36}$ The problem of missing strings after PPIUDCS insertion is of considerable importance with regard to advancing this method in the GS. There have been various approaches to attempt to resolve this problem. In one study vicryl was used to lengthen the threads. ${ }^{14}$ The use of absorbable material which ensures that the strings remain visible, but subsequently absorb so that they are not too long, may be a solution. These techniques are among those which have the capacity to expand access in the GS and indeed worldwide.

The use of 6-week controls has created a new group of post-CS IUD recipients for study. While the insertion of IUDs at the 6-week follow-up after CS is not new, we added the results of insertions at $42-90$ days post- $\mathrm{CS}^{26}$ and the 6 -week post-CS insertions in the newer studies. The difference between the post-CS at around 6 weeks and the truly interval insertions ( $\geq 90$ days post-CS) is the risk of certain specialized complications, eg, perforations. ${ }^{44}$ For this reason we consider that this group should be examined separately from PPIUDCS and IIUDCS. There is as yet no study reporting the outcomes of insertions performed exclusively in the 40-45 days post-CS period.

\section{Conclusion}

PPIUDCS has many practical advantages. The recipient can leave with the IUD in place and will be protected from pregnancy even if she does not attend follow-up, provided the IUD remains in place. Further evidence from systematic review of recent studies is providing us with new information to help make this a more acceptable option for women 
in the GS and elsewhere. In order to expand access to this procedure there are three main problems to be solved, namely: 1) prevent expulsion - whether by device design or suture technique; 2) ensure that strings are visible, and if possible do not require adjustment; and 3) reduce puerperal bleeding - hopefully by the use of cheaper hormone releasing devices, which should soon become available.

\section{List of abbreviations}

CS, cesarean section; IUD, intrauterine contraceptive device; LARC, long-acting reversible contraceptive; GS, global south; PPIUDCS, post-placental IUD at CS; RCT, randomized controlled trial; IIUDCS, interval insertion of IUD after CS; LNG, levonorgestrel.

\section{Disclosure}

The authors report no conflicts of interest in this work.

\section{References}

1. Winner B, Peipert JF, Zhao Q, et al. Effectiveness of long-acting reversible contraception. $N$ Eng J Med. 2012;366(21):1998-2007.

2. Mavranezouli I; LARC Guideline Development Group. The costeffectiveness of long-acting reversible contraceptive methods in the UK: analysis based on a decision-analytic model developed for a National Institute for Health and Clinical Excellence (NICE) clinical practice guideline. Hum Reprod. 2008;23(6):1338-1345.

3. Glasier A. Implantable contraceptives for women: effectiveness, discontinuation rates, return of fertility, and outcome of pregnancies. Contraception. 2002;65(1):29-37.

4. Funk S, Miller MM, Mishell DR Jr, et al. Safety and efficacy of Implanon, a single-rod implantable contraceptive containing etonogestrel. Contraception. 2005;71(5):319-326.

5. Betrán AP, Merialdi M, Lauer JA, et al. Rates of caesarean section: analysis of global, regional and national estimates. Paediatr Perinat Epidemiol. 2007;21(2):98-113.

6. Goldstuck ND, Steyn PS. Intrauterine contraception after cesarean section and during lactation: a systematic review. Int J Womens Health. 2013; 5:811-818

7. Bhutta SZ, Butt IJ, Bano K. Insertion of intrauterine contraceptive device at caesarean section. J Coll Physicians Surg Pak. 2011;21(9): 527-530.

8. Santos AR, Bahamondes MV, Hidalgo MM, Atti A, Bahamondes L, Monteiro I. Pain at insertion of the levonorgestrel-releasing intrauterine system in nulligravida and parous women with and without cesarean section. Contraception. 2013;88(1):164-168.

9. López-Farfan JA, Hernandez-Gonzalez A, Vélez-Machorro IJ, VázquezEstrada LA. A comparative, randomized study of levonorgestrel intrauterine system (LNG-IUS) vs Copper T 380 A intrauterine device applied during cesarean section. Open J Obstet Gynecol. 2012;2(2): 151-155.

10. Elsedeek MS. Puerperal and menstrual bleeding patterns with different types of contraceptive device fitted during elective caesarean section. Int J Gynaecol Obstet. 2012;116(1):31-34.

11. Elsedeek MS. Five-year follow-up of two types of contraceptive device fitted during elective cesarean delivery. Int J Gynaecol Obstet. 2015;130(2): 179-182.

12. Lester F, Kakaire O, Byamugisha J, et al. Intracesarean insertion of the Copper T380A versus 6 weeks postcesarean: a randomized clinical trial. Contraception. 2015;91(3):198-203.
13. Braniff K, Gomez E, Muller R. A randomised clinical trial to assess satisfaction with the levonorgestrel-releasing intrauterine system inserted at caesarean section compared to postpartum placement. Aust N Z J Obstet Gynaecol. 2015;55(3):279-283.

14. Ragab A, Hamed HO, Alsammani MA, et al. Expulsion of Nova-T380, Multiload 375, and Copper-T380A contraceptive devices inserted during cesarean delivery. Int J Gynaecol Obstet. 2015;130(2):174-178.

15. Levi EE, Stuart GS, Zerden ML, Garrett JM, Bryant AG. Intrauterine device placement during caesarean delivery and continued use 6 months postpartum: a randomized controlled trial. Obstet Gynecol. 2015; 126(1):5-11.

16. Ibrahim ZM, Sayed Ahmed WA. Sublingual misoprostol prior to insertion of a T380A intrauterine device in women with no previous vaginal delivery. Eur J Contracept Reprod Health Care. 2013;18(4):300-308.

17. Whitaker AK, Endres LK, Mistretta SQ, Gilliam ML. Postplacental insertion of the levonorgestral intrauterine device after cesarean delivery vs. delayed insertion: a randomized controlled trial. Contraception. 2014;89(6):534-539.

18. Stoddard AM, Xu H, Madden T, Allsworth JE, Peipert JF. Fertility after intrauterine device removal: a pilot study. Eur J Contracept Reprod Health Care. 2015;20(3):223-230.

19. Gueye M, Gaye YF, Diouf AA, et al. [Trancesarean intra-uterine device. Pilot study performed at Dakar teaching hospital]. Dispositif intra-uterin mis en place en cours de cesarienne. Etude pilote realisee au centre hospitalier universitaire de Dakar. J Gynecol Obstet Biol Reprod (Paris). 2013;42(6):585-590. French.

20. Tjahjanto H, Haryuni IT. Hang-up IUD, new technique for suturing CuT-380A IUD to uterine fundus in immediate postplacental insertion during cesarean delivery: twelve months follow up. Indones $J$ Obstet Ginecol. 2014;2-31:132-139.

21. Singal S, Bharti R, Dewan R, et al. Clinical outcome of postplacental Copper T 380A insertion in women delivering by caesarean section. J Clin Diagn Res. 2014;8(9):OC01-OC04.

22. Moher D, Liberati A, Tetzlaff J, Altman DG; PRISMA Group. Preferred reporting items for systematic reviews and meta-analyses: the PRISMA statement. PLoS Med. 2009;6(7):e1000097.

23. Zhang H, Fang G, Zhou C, et al. [Study on GyneFix PP IUD insertion during cesarean section]. Chinese J Fam Plann. 2004;12(8):481-482. Chinese.

24. Quin LJ. [Fix Cu220C-M and Delta-T-Cu220C inserted immediately during cesarean section: a comparative randomised clinical study]. Chinese J Fam Plann. 1994;1(9):16-18. Chinese.

25. Sastrawinata $\mathrm{S}$, Haswidi E. Pemasangan IUD sewaktu sectio caesarea di RS Hasan Sadikin Bandung selama periode 3 tahun (1975-1977). [The application of IUD during Cesarean Section at Hasan Sadikin Hospital, Bandung, during the three year period (1975-1977)]. In: Naskah lengkap sidang ilmiah Kongres Obstetri Ginekologi Indonesia Ke IV, Yogyakarta, 10-15 Juni 1979. P.D. Lukman; 1979:84-91.

26. Tao S. [IUD insertion at $42-90$ days after caesarean section: a two year prospective study of safety and efficacy]. Chinese J Fam Plann. 1994;2(10):91-94. Chinese.

27. Puzey M. Mirena at caesarean section. Eur J Contracept Reprod Health Care. 2005;10(3):164-167.

28. Ruiz-Velasco V, Garcia C, Castro H. Cesarean section IUD insertion. Contracept Deliv Syst. 1982;3(1):21-24.

29. Lara R, Sanchez RA, Aznar R. [Application of intrauterine device through the incision of the cesarean section]. Aplicacion del dispositivo intrauterino a traves de la incision de la cesarea. Ginecol Obstet Mex. 1989;57:23-27. Spanish.

30. Alvarez Pelago J, Borbolla Sala ME. [IUD insertion during cesarean section and its most frequent complications]. DIU transcesarea y sus complicaciones mas frecuentes. Ginecol Obstet Mex. 1994;62:330-335. Spanish.

31. Van Kets H, Thiery M, Van der Pas H. IUD insertion during cesarean section. Adv Contracept. 1985;1(4):337-339.

32. Celen S, Sucak A, Yildez Y, Danisman N. Immediate postplacental insertion of an intrauterine contraceptive device during cesarean section. Contraception. 2011;84(3):240-243. 
33. Letti Müller AL, Lopes Ramos JG, Martins-Costa SH, et al. Transvaginal ultrasonographic assessment of the expulsion rate of intrauterine devices inserted in the immediate postpartum period: a pilot study. Contraception. 2005;72(3):192-195.

34. Levi E, Cantillo E, Ades V, Banks E, Murthy A. Immediate postplacental IUD insertion at caesarean delivery: a prospective cohort study. Contraception. 2012;86(2):102-105.

35. Celen S, Moroy P, Sucak A, Aktulay A, Danisman N. Clinical outcomes of early postplacental insertion of intrauterine contraceptive devices. Contraception. 2004;69(9):279-282.

36. Nelson A, Chen S, Eden R. Intraoperative placement of the Copper $\mathrm{T}-380$ intrauterine devices in women undergoing elective caesarean delivery: a pilot study. Contraception . 2009;80(1):81-83.

37. Chi IC, Zhou SW, Balogh S, Ng K. Post-cesarean section insertion of intrauterine devices. Am J Pub Health. 1984;74(11):1281-1282.

38. Chi IC, Ji G, Siemens AJ, Waszak CS. IUD insertion at cesarean section - the Chinese experience. Adv Contracept. 1986;2(2): $145-153$.
39. Liu BH, Zhang LY, Zhang BR. Intrauterine contraceptive device insertion with suture fixation at cesarean section. Chin Med J (Engl). 1983;96(2):141-144.

40. Zerzavy FM. Use of intrauterine contraceptive devices in the postpartum period. Am J Public Health Nations Health. 1967;57(1):28-33.

41. Farley TM, Rosenberg MJ, Rowe PJ, Chen JH, Meirik O. Intrauterine devices and pelvic inflammatory disease: an international perspective. Lancet. 1992;339(8796):785-788.

42. Goldstuck ND, Wildemeersch D. Prevention of intrauterine contraceptive device expulsion and intolerance: Determination of the anchor mechanism. Clin Obstet Gynecol Reprod Med. 2017;3(1):1-8.

43. Wildemeersch D, Goldstuck ND, Hasskamp T. Current status of frameless anchored IUD for immediate intracesarean insertion. Dev Period Med. 2016;20(1):7-15.

44. Goldstuck ND, Wildemeersch D. Role of uterine forces in intrauterine device embedment, perforation and expulsion. Int $J$ Womens Health. 2014;6:735-744.
International Journal of Women's Health

\section{Publish your work in this journal}

The International Journal of Women's Health is an international, peerreviewed open-access journal publishing original research, reports, editorials, reviews and commentaries on all aspects of women's healthcare including gynecology, obstetrics, and breast cancer. The manuscript management system is completely online and includes

\section{Dovepress}

a very quick and fair peer-review system, which is all easy to use. Visit http://www.dovepress.com/testimonials.php to read real quotes from published authors. 